\title{
The Study of Functional and Rheological Properties of Teff [Eragrostis Teff (Zucc.) Trotter] Grain Flour Varieties
}

\author{
Gashaw Abebaw Tsegaye ${ }^{1}$, Solomon Abera ${ }^{2}$ \\ ${ }^{1}$ Department of Food Process Engineering, Wolkite University, Wolkite, Ethiopia \\ ${ }^{2}$ Department of Food Technology and Process Engineering, Haramaya University, Dridaw, Ethiopia
}

Email address:

gashaw11abebaw@gmail.com (G. A. Tsegaye)

\section{To cite this article:}

Gashaw Abebaw Tsegaye, Solomon Abera. The Study of Functional and Rheological Properties of Teff [Eragrostis Teff (Zucc.) Trotter] Grain Flour Varieties. International Journal of Food Engineering and Technology. Vol. 4, No. 1, 2020, pp. 1-8.

doi: $10.11648 /$ j.ijfet.20200401.11

Received: January 21, 2020; Accepted: February 25, 2020; Published: March 6, 2020

\begin{abstract}
This study was conducted to generate information on some functional and rheological properties of teff [Eragrostis teff (Zucc.) Trotter] grain Flour varieties. Six teff varieties namely Quncho (DZ-Cr-387), Felagot (DZ-Cr-442), Tesfa (DZ-Cr457), Kora (DZ-Cr-438), Dukem (DZ-Cr-425) and Dagme (DZ-Cr-43Bvarieties) were considered and their selection was based on their recent year coverage area and the expected future expansion. Each variety was studied. The highest value of functional properties of teff flours which included water and oil absorption capacity, swelling power, dispersibility and water solubility index of the teff flour were $0.99 \mathrm{~g} / \mathrm{g}, 1.42 \mathrm{ml} / \mathrm{g}, 11.99 \%, 74 \%$ and $19.61 \%$ for DZ-Cr-387, DZ-Cr-438, DZ-Cr-438, DZ-Cr-438 \& DZ-Cr-457 andDZ-Cr-438 varieties respectively. The pasting properties of the teff flour such as pasting temperature, peak time, peak viscosity, final viscosity, break down viscosity, trough and set back viscosity values had ranged from 76 to $80.33^{\circ} \mathrm{C}, 5.13$ to $6.17 \mathrm{~min}, 880$ to $1650 \mathrm{cP}, 1511$ to $1721 \mathrm{cP}, 340.33$ to $800 \mathrm{cP}, 540$ to 880 and 370.33 to $971 \mathrm{cP}$. The farinograph values had ranged from 47.37 to $50.85 \%, 4.67$ to $5.99 \mathrm{~min}, 3.62$ to $4.24 \mathrm{~min}, 58.18$ to $76.99 \mathrm{FU}$ and 70.67 to $82.56 \mathrm{FU}$ for water absorption, dough development time, dough stability time, mixing tolerance index and farinograph quality number respectively. There were significant $(P<0.05)$ differences among the varieties except dough stability time.
\end{abstract}

Keywords: Teff Grains and Flour, Pasting Properties, Functional Properties, Physical Properties, Rheological Properties

\section{Introduction}

Teff is a unique durable crop grown over a wide range of environmental conditions in Ethiopia and has been utilized as food and supplements for majority of the human diet in Ethiopia [1]. Teff is an ancient tropical cereal that has its center of origin and diversity in the northern Ethiopian highlands, from where it is believed to have been domesticated. In Ethiopia; it is a major food grain, mainly used to make injera, a traditional fermented Ethiopian pancake. Teff grain size is known to be extremely small with mean length ranging from0.61-1.17 $\mathrm{mm}$ and mean width ranging from 0.13-0.59 $\mathrm{mm}$, which gives an average thousand kernel weight of 0.264 gram [1]. Teff grain anatomy studied by [2] indicates that the embryo, rich in protein and lipid, occupies a relatively large part of the grain. The aleurone layer is one cell thick and rich in protein lipid bodies. The testa is located within the pericarp and its thickness varies with the color of the grain. The testa of red teff is thicker than white teff and it is filled with pigmented material, suggested to be tannins or polyphenol compounds [3]. The teff grain proteins offer an excellent balance among the essential amino acids [4]. Teff is regarded as a "healthy food", suitable for its employment in novel foods such as baby foods and gluten-free based goods [5]. The attention to teff has been recently increased because of its health benefits. Teff has an attractive nutritional profile having significant levels of minerals including calcium, iron, magnesium, phosphorus, potassium, and zinc. Also, teff is rich in vitamins, such as thiamin (B1), riboflavin (B2), vitamin A and K. Furthermore, teff is high in proteins including all 8 essential amino acids that is superior in lysine than wheat or barley along with its high carbohydrate sand fiber contents. Teff is beneficial for those who are lactose intolerant since it is gluten-free. Red teff grains are greatly recommended for the improvement of osteoporosis and bone healing conditions [6].

Currently, consumer's preference towards baked goods 
with additional (functional and nutritional) value is increasing, forcing food industries to look for more natural nutrient-dense alternatives like grain teff flour for use by the people affected by celiac disease because it is a gluten free cereal grain with high potential. The growing demand for products from teff grain flour due to its nutritional and health benefits is raising the interest of modern food industries and bulk flour milling, flour handling and processing operations of this cereal grain is inevitable. Therefore generation of some information concerning of engineering properties of teff grain and its flour; to investigate and provide concise information and data on selected physical, functional, thermal and rheological properties of teff grain and its flour is considered to be important [7].

\section{Literature Review}

\subsection{Farinograph}

Farinograph is used to measure the evolution of dough under specific kneading conditions after it was brought to standard consistency of 500 F. U. The principle of Farinograph operation is based on the resistance of dough to the kneader shaft. The resistant moment to the kneader shaft has increasing variation when mixing the components, hydrating of flour particles, dough formation and development, up to a maximum value, close to the value of dough normal consistency. Then, the variation of moment to the shaft, respectively dough consistency remain approximately constant, in the stability phase of the dough which can be maintained for longer or shorter time depending on the characteristics of flour. Graphic recording of the moment (dough consistency) during kneading with the farinograph device is called Farinograph [8]. The farinograph test is one of the most commonly used flour quality tests in the world. The results are used as parameters in formulation to estimate the amount of water required to make dough, to evaluate the effects of ingredients on mixing properties, to evaluate flour blending requirements, and to check flour uniformity. The results are also used to predict processing effects, including mixing requirements for dough development, tolerance to over mixing, and dough consistency during production. Farinograph results are also useful for predicting finished product texture characteristics. For example, strong dough mixing properties are related to firm product texture [9].

Water absorption is the amount of water required to center the farinograph curve on the 500 Brabender units (BU) line. This relates to the amount of water needed for a flour to be optimally processed into end products. Water absorption is expressed as a percentage [10].

Peak Time indicates dough development time; beginning at the moment water is addeduntil the dough reaches maximum consistency. This gives an indication of optimummixing time under standardized conditions. Peak time is expressed in minutes. Arrival Time is the time when the top of the curve touches the 500-BU line. Thisindicates the rate of flour hydration (the rate at which the water is taken up by the flour). Arrival time is expressed in minutes.

Departure Time is the time when the top of the curve leaves the 500-BU line. Thisindicates the time when the dough is beginning to break down and is an indication ofdough consistency during processing. Departure time is expressed in minutes. Stability Time is the difference in time between arrival time and departure time. Thisindicates the time the dough maintains maximum consistency and is a good indication ofdough strength. Stability time is expressed in minutes.

Mixing Tolerance Indexis the difference in BU value at the top of the curve atpeak time and the value at the top of the curve 5 minutes after the peak. This indicates thedegree of softening during mixing. Mixing tolerance index is expressed in Brabender units (BU). Weak gluten flour has a lower water absorption and shorter stability time thanstrong gluten flour adapted from AACC, 2000.

Farinograph quality numberis the point of the curve in which the curve hasdecreased by $30 \mathrm{FU}$ after the maximum (based on the line of the diagram). Thus weakflour weakens early and quickly giving low quality number. Strong flour weakens lateand slowly indicting a high quality number [11].

\subsection{Pasting Properties}

This property is very important to know the flour or starch characteristics of a cereal orstarchy product. They are useful to predict the behavior of the flour in baking and brewing process [12]. Pasting properties of starch are the phenomena involving granular cooking, swelling, and total disruption of granules. It has been used to quantify cold-swelling of 'cooked' component, raw component that paste's during test and overall viscosity that indicates degree of starch dextrinization [13]. The pasting properties are important indices in predicting the pasting behavior during and after cooking, [14]. The pasting character predicts the processing qualities (cooking temperature and time, thickening ability, temperature, pressure, shear induce viscosity breakdowns, gelling and reterogradation tendencies over the storage durations) of starch based raw material food ingredients. The pasting character is fundamentally determined by the starch granule composition and its nature (ultrastructures) and is influenced by the non-starch flour components [1]. For example to determine these characteristics, it is necessary to use a Rapid Visco Analyzers, and the main characteristics are:

Pasting temperature. It indicates the minimum temperature required to cook starch [15].

Peak viscosity is the maximum viscosity attained by gelatinized starch during heating in water. It indicates the water binding capacity of the starch granule [16].

Breakdown viscosity is measurement of the vulnerability or susceptibility of the cooked starch to disintegration. The high breakdown in viscosity will reduce the ability of the starch sample to withstand heating and shear stress during cooking.

Trough viscosity is related to the ability of the starch paste to form a gel after cooling. Gelation occurs with junction zone formation mostly through hydrogen bonding, reassociating the hydrated and dispersed starch molecules, and 
can vary with the botanical sources of the starch, amylose content and formation of amylose-lipid complexes, amount of water, other ingredients like proteins and temperature of cooling [17]. High-amylose (linear) starches re-associate more readily than high amylopectin branched starches.

Setback viscosity is a measure of recrystallization of gelatinized starch during cooling. High setback value gave lower reterogradation during cooling and the lower staling rate of the products made from the starch.

Final viscosityindicates the abilityof the starch to form a viscous paste [18].

\section{Materials and Methods}

\subsection{Experimental Site}

These experiments were done at Wolkite University,
College of Engineering and Technology in Food Process Engineering Laboratory.

\subsection{Experimental Materials}

The six-teff varieties of Quncho (DZ-Cr-387), Felagot (DZ-Cr-442), Tesfa (DZ-Cr-457), Kora (DZ-Cr-438), Dukem (DZ-Cr-425) and Dagme (DZ-Cr-43B) were obtained from Debre Zeit Agricultural Research Center of the Ethiopian Institute of Agricultural Research (EIAR). These teff varieties were released by the National teff Improvement Program of the Ethiopian Institute of Agricultural Research (EIAR). The six teff varieties were selected based on the color, popularity among the teff grain consumers and the teff grain farming community, high yield, and that some are released recently [19].

Table 1. Teff Grain Varieties.

\begin{tabular}{lllll}
\hline No & Variety name & Common name & Seed color & Year of release \\
\hline 1 & DZ-Cr-387 & Quncho & Very White & 2017 \\
2 & DZ-Cr-442 & Felagot & Red & 2017 \\
3 & DZ-Cr-457 & Tesfa & Pale White & 2017 \\
4 & DZ-Cr-438 & Kora & White & 2014 \\
5 & DZ-Cr-425 & Dukem & White & 2016 \\
6 & DZ-Cr-43B & Dagme & White & 2016 \\
\hline
\end{tabular}

\subsection{Statistical Analysis}

Data was analyzed by the analysis of variance (ANOVA) procedures using statically analysis of software (SAS) for windows version 9.0. Least significant differences (LSD) are using for Fisher mean comparison tests. Significance is accepting at $(\mathrm{P}<$ $0.05)$

\section{Results and Discussions}

Table 2. Functional Properties of Teff Flour.

\begin{tabular}{|c|c|c|c|c|c|}
\hline Varieties & WAC (g/g) & $\mathrm{OAC}(\mathrm{ml} / \mathrm{g})$ & SP (\%) & DIS (\%) & WSI (\%) \\
\hline DZ-Cr-387 & $0.99 \pm 0.01^{\mathrm{a}}$ & $1.27 \pm 0.01^{\mathrm{c}}$ & $10.24 \pm 0.27^{\mathrm{c}}$ & $73.67 \pm 1.53^{\text {ba }}$ & $19.61 \pm 0.18^{b}$ \\
\hline DZ-Cr-442 & $0.98 \pm 0.01^{\text {ba }}$ & $1.18 \pm 0.01^{\mathrm{e}}$ & $8.37 \pm 0.13^{\mathrm{e}}$ & $72.00 \pm 1.00^{\mathrm{b}}$ & $17.44 \pm 0.12^{\mathrm{e}}$ \\
\hline DZ-Cr-457 & $0.96 \pm 0.01^{b}$ & $1.24 \pm 0.01^{\mathrm{d}}$ & $8.88 \pm 0.36^{\mathrm{d}}$ & $74.00 \pm 1.00^{\mathrm{a}}$ & $18.69 \pm 0.34^{\mathrm{c}}$ \\
\hline DZ-Cr-425 & $0.91 \pm 0.01^{\mathrm{d}}$ & $1.08 \pm 0.02^{\mathrm{f}}$ & $10.91 \pm 0.39^{b}$ & $73.00 \pm 1.00^{\text {ba }}$ & $19.51 \pm 0.18^{b}$ \\
\hline DZ-Cr-43B & $0.93 \pm 0.01^{\mathrm{c}}$ & $1.32 \pm 0.01^{\mathrm{b}}$ & $9.21 \pm 0.22^{\mathrm{d}}$ & $72.00 \pm 1.00^{\mathrm{b}}$ & $17.96 \pm 0.06^{\mathrm{d}}$ \\
\hline LSD & 0.02 & 0.02 & 0.47 & 1.97 & 0.36 \\
\hline
\end{tabular}

Note: $\mathrm{WAC}=$ Water absorption capacities, $\mathrm{OAC}=\mathrm{Oil}$ absorption capacity, $\mathrm{SP}=$ Swelling power, DIS=Dispersability, WSI=Water Solubility index. Within a column, values with different superscript lettershave significant $(\mathrm{P}<0.05)$ differences.

\subsection{Swelling Power}

The measured swelling power of the teff flour is presented in Table 2. The values were $10.24,8.37,8.88,11.99,10.91$ and $9.21 \%$ for the varieties Quncho (DZ-Cr-387), Felagot (DZ-Cr-442), Tesfa (DZ-Cr-457), Kora (DZ-Cr-438), Dukem (DZ-Cr-425) and Dagme (DZ-Cr-43B), respectively. There were significant $(\mathrm{P}<0.05)$ differences among the varieties, with Kora (DZ-Cr-438) having the highest value (11.99\%) whereas, Felagot (DZ-Cr-442) the lowest value (8.37\%). These results were found to be within range between 7.7 and $12.5 \%$ which were reported by [20]. They indicated swelling power is a measure of hydration capacity of starch, because the determination is a weight measure of swollen starch granules and their occluded water. Food eating quality is often connected with retention of water in the swollen starch granules [10]. Swelling power and solubility of starch granules also play an important role in contributing to the pasting and rheological behavior in most starchy products. Moorthy [21] reported that the swelling power of flour granules is an indication of the extent of associative forces within the granule. Swelling power is also related to the water absorption index of the starch-based flour during heating [12]. Therefore, the higher the swelling power, the 
higher the associate forces. The variation in the swelling power indicates the degree of exposure of the internal structure of the starch present in the flour to the action of water [13].

\subsubsection{Water Absorption Capacity}

The measured water absorption capacities of different teff flour are presented in Table 2 . The values were 0.99, 0.98, $0.96,0.89,0.91$ and $0.93 \mathrm{~g} / \mathrm{g}$ for the varieties Quncho (DZCr-387), Felagot (DZ-Cr-442), Tesfa (DZ-Cr-457), Kora (DZ-Cr-438), Dukem (DZ-Cr-425) and Dagme (DZ-Cr-43B), respectively. There were significant $(\mathrm{P}<0.05)$ differences among the varieties. Quncho (DZ-Cr-387) having the highest values $(0.99 \mathrm{~g} / \mathrm{g})$ of water absorption among the varieties studied because Proteins (consist of subunits structure and dissociates on heating as observed by Granito [22]. Dev and Quensil, (1988) reported that protein subunit have more water binding sites (increase in the number of hydrophilic groups) which are the primary sites of water binding of protein. Kora (DZ-Cr-438) showed thelowest value (0.89 $\mathrm{g} / \mathrm{g}$ ). These results were foundin harmonywith previous studies conducted by [23]. The high water absorption capacity has been attributed to loose structure of starch polymers while low water absorption capacity value indicates the compactness of molecular structure [24].

\subsubsection{Oil absorption Capacity}

The oil absorption capacity results of different teff flours are presented in Table 1 . There were significant $(\mathrm{P}<0.05)$ differences among the varieties with values of $1.27,1.18$, 1.24, 1.42, 1.08 and $1.32 \mathrm{ml} / \mathrm{g}$ for Quncho (DZ-Cr-387), Felagot (DZ-Cr-442), Tesfa (DZ-Cr-457), Kora (DZ-Cr-438), Dukem (DZ-Cr-425) and Dagme (DZ-Cr-43B) teff varieties. Kora (DZ-Cr-438) having the highest value $(1.42 \mathrm{ml} / \mathrm{g})$ whereas Dukem (DZ-Cr-425) the lowest value $(1.08 \mathrm{ml} / \mathrm{g})$. These results were found to be within range between 1.00 and $1.55 \mathrm{ml} / \mathrm{g}$ ) reported by [25]. Oil present food products improves their mouth feel and flavor retention. The oil binding capacity of food protein depends upon the intrinsic factors like amino acid composition, protein conformation and surface polarity or hydrophobicity. The ability of the proteins of the flour to bind with oil makes it useful in foodsystem where optimum oil absorption is desired. This makes the powder to have potentialfunctional uses in foods such as bakery products. The oil absorption capacity also makes the flour suitable in facilitating enhancement in flavor and mouth feel when used in food preparation. In addition fat increases the leavening power of the baking powder in the batter and improves the texture of the baked product.

\subsubsection{Dispersbility}

The property of Dispersability determines the tendency of flour to move apart from water molecule and shows its hydrophobic interaction. [26] Reported that water absorption is influenced by processing methods affecting starch gelatinization and swelling power. The measured Dispersability of different teff flour are Presented in Table 1. The values were 73.67, 72. 00, 74.00, 74.00, 73.00 and $72.00 \%$ for varieties Quncho (DZ-Cr-387), Felagot (DZ-Cr442), Tesfa (DZ-Cr-457), Kora (DZ-Cr-438), Dukem DZ-Cr425) and Dagme (DZ-Cr-43B), respectively. There were no significant $(\mathrm{P}>0.05)$ differences among the varieties. Present values were fairly compatible with results of Ashogbon and Akintayo, (2012), who reported values of 70.33-99.44\% Dispersability for pearl millet flour [27].

\subsubsection{Water Solubility Index}

Water solubility index is important parameter often used as an indicator of degradation of molecularcomponents. WSI measures the amount of soluble components released from theprotein and other molecules after extrusion. The water solubility index results of teff flours are presented in Table 1. The values were 19.61, 17.44, 18.69, 19.99, 19.51 and $17.96 \%$ for varieties Quncho (DZ-Cr-387), Felagot (DZ-Cr442), Tesfa (DZ-Cr-457), Kora (DZ-Cr-438), Dukem (DZCr-425) and Dagme (DZ-Cr-43B), respectively withsignificant $(\mathrm{P}<0.05)$ differences among the varieties. Kora (DZ-Cr-438) hadthe highestvalue of $19.99 \%$ whereas Felagot (DZ-Cr-442) the lowest value of (17.44\%) water solubility index among the varieties. These results were found to be within the range between 14.39 and $20.33 \%$ which was reported by [28] for cassava flour. The low water solubility index offlour could be attributed to the possibility of amylase complex with especially lipids in flour starch preventing it from dissolving in solution. Other factors could be the high stability of flour starch amylopectin structure; hence, preventing it from possible degradation during heating [29].

Table 3. Pasting Properties of Flour.

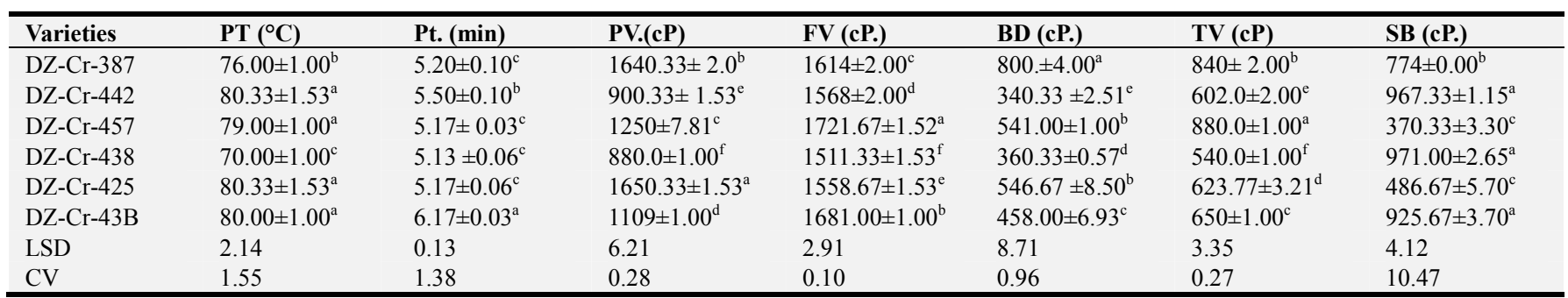

\subsection{Pasting Temperatures}

The measured pasting temperatures of the teff flours dough are presented in Table 3. There were significant $(\mathrm{P}<0.05)$ differences. Varieties, Felagot, Tesfa, Dukem and Dagme exhibited pasting temperatures of $80.33,79.00,80.33$ and 
$80.00^{\circ} \mathrm{C}$, respectively with no significant differences among them. Their values is found to be statistically higher than the $76.00^{\circ} \mathrm{C}$ belonging to variety Quncho which in turn is statically higher than the lowest value $70.00^{\circ} \mathrm{C}$ of variety Kora. Pasting temperature of different flour varies due to various sizes of the teff starch granules. Larger teff flour granules are associated with lower pasting temperature and high swelling properties [30]. In this observation, Dukem (DZ-Cr-425) and Felagot (DZ-Cr-442) flour had smaller granules size than the other varieties, thus may have contributed to the higher pasting temperature. Higher pasting temperature also indicates a greater structural rigidity of the flour [31]. The Pasting temperature found in this work is somehow similar to the reported RVA pasting temperatures between $64.1^{\circ} \mathrm{C}$ and $90.8^{\circ} \mathrm{C}$ for five teff flour starches [32].

\subsubsection{Peak Time}

The peak time results of teff flours are presented in Table 2 . The time at which peak viscosity occurred in minutes is termed peak time [33]. The values were 5.20, 5.50, 5.17, 5.13, 5.17 and $6.17 \mathrm{~min}$ for varieties Quncho (DZ-Cr-387), Felagot (DZ-Cr-442), Tesfa (DZ-Cr-457), Kora (DZ-Cr-438), Dukem (DZ-Cr-425) and Dagme (DZ-Cr-43B), respectively. There were significant $(\mathrm{P}<0.05)$ differences among the varieties. Dagme (DZ-Cr-43B) having the highest value (6.17 $\mathrm{min}$ ) followed by the $5.50 \mathrm{~min}$ of variety Felagot. The rest of the varieties had peak time values of 5.13 to 5.20 min with no significant $(\mathrm{P}>0.05)$ differences among them. These results showed slightly longer time thanthe RVA Pasting time reported (6.00-3.43 $\mathrm{min})$ for teff flour by [32]. Short peak time observed in the flour may be due to reduced starch content. However, short peak time is indicative of its ability to cook fast.

\subsubsection{Peak Viscosity}

The peak viscosity results of teff flour values had ranged from 880 to $1650.33 \mathrm{cp}$. Dukem (DZ-Cr-425) having the highestvalue $(1650.33 \mathrm{cP})$ whereas Kora (DZ-Cr-438) the lowest value $(880 \mathrm{cP})$. There were significant $(\mathrm{P}<0.05)$ differences among the varieties. The peak viscosity is indicative of the strength of pastes, which are formed from gelatinization during processing in food applications. It also reflects the extent of granule swelling [34] and provides an indication of the viscous load likely to be encountered during mixing. The higher the peak viscosity the more is the swelling index, while low paste viscosity is indicative of higher solubility as a result of starch degradation or dextrinization [35]. The PV indicates the thickening ability and water holding capacity of the pasted flour and reflects the eating quality of the food products to be made as reported by [36]. The final viscosity results of the teff flours are presented in Table 3. The values had ranged from 1511.33 to 1721.67 cP Tesfa (DZ-Cr-457) having the highest value $(1721.67 \mathrm{cP})$ and Kora (DZ-Cr-438) the lowest value (1511.33 cP). There were significant $(\mathrm{P}<0.05)$ differences among the final viscositiesdue to the varieties. Final viscosities are important in determining ability of the flour sample to form a gel during processing andit is the most commonly used parameters to define a particular sample quality [12]. Final viscosity shows the ability of the material to form a viscous paste and it is mainly determined by the retro gradation of soluble amylose in the process of cooling.

\subsubsection{Breakdown Viscosity}

The measured breakdown viscosity of the teff flours are presented in Table 2. The values had ranged from 340.33 to $800 \mathrm{cP}$. There were significant $(\mathrm{P}<0.05)$ differences among the varieties. Quncho (DZ-Cr-387) had the highest value $(800 \mathrm{cP})$ while Felagot (DZ-Cr-442) the lowest value (340.33 cP). Quncho (DZ-Cr-387) breakdown viscosity larger than that of the other varieties. This means that these teff varieties showed the highest disintegration degree of the swollen systems and alignment of amylase and other linear components in the direction of shear while the lowest value of breakdown viscosity in Felagot (DZ-Cr-442). Breakdown viscosity reflects the stability of the paste during processing. The higher the breakdown in viscosity, the lower the ability of the starch in the flour samples to withstand heating and shear stress during [33]. It was also reported by [37] that high breakdown value indicates relative weakness of the swollen starch granules against hot shearing while low breakdown values indicate that the starch in question possesses crosslinking properties. The break down viscosity measures the differences between peak viscosity and trough viscosity achieved during the high temperature $\left(80.33^{\circ} \mathrm{C}\right.$ for $\left.5.17 \mathrm{~min}\right)$ holding duration and shows the relative differences of shear thinning and degree of disintegration of the swollen systems. Teff flour starch pasting are shear tolerant and thus had a potential for use in foods processed under high shear conditions.

The results of trough viscosity values are displayed in Table 3. The values had ranged from 540 to $880 \mathrm{cP}$. Tesfa (DZ-Cr-457) had the highest value $(880 \mathrm{cP})$ and Kora (DZ$\mathrm{Cr}-438)$ the lowest value were $(450 \mathrm{cP})$. There were significant $(\mathrm{P}<0.05)$ differences among the varieties.

\subsubsection{Setback Viscosity}

The measured setback viscosity of the teff flours values are presented in Table 2. The values had ranged from 370.33 to $971 \mathrm{cP}$. Kora (DZ-Cr-438) had the highest value $(971 \mathrm{cP})$ where as Tesfa (DZ-Cr-457) had lowest value $(370.33 \mathrm{cP})$. There were significant $(\mathrm{P}<0.05)$ differences among the varieties. The SBpredicts the degree of gelatin and the gradual reterogradation tendencies on cooling and storage of the teff flour starch pasted system. Teff starch was known to have less thickening ability, shear tolerance and slow setback than commercial normal maize starch reported by [1] on the RVA pasting and similar is also seen in the Bra bender amyl graph pasting. Teff starches were also known to have slow reterogradation tendencies on the refrigeration and freeze storages and freeze-thaw cycle treatments than the maize starches [38]. The remarkably lower SV of the teff flours with respect to wheat and rice flours is related to amylase retro gradation and confirm that teff flours retrograde extent than other cereals. Such lower reterogradation tendency in the teff flours could make them to be advantageous in formulation of 
Farinograph Test

Table 4. Farinograph Test.

\begin{tabular}{|c|c|c|c|c|c|}
\hline Varieties & WA (\%) & DDT (min) & DST (min) & MIT (FU.) & FQN (FU.) \\
\hline DZ-Cr-387 & $47.37 \pm 0.33^{b}$ & $4.67 \pm 0.28^{\mathrm{d}}$ & $3.99 \pm 0.12^{\mathrm{a}}$ & $68.69 \pm 0.34^{\mathrm{c}}$ & $77.94 \pm 0.32^{\mathrm{c}}$ \\
\hline DZ-Cr-442 & $50.11 \pm 0.11^{\mathrm{a}}$ & $5.28 \pm 0.38^{b}$ & $3.64 \pm 0.16^{\mathrm{a}}$ & $74.58 \pm 0.97^{\mathrm{b}}$ & $77.47 \pm 0.59^{c}$ \\
\hline DZ-Cr-457 & $48.14 \pm 0.39^{b}$ & $5.03 \pm 0.07^{\mathrm{b}}$ & $3.62 \pm 1.64^{\mathrm{a}}$ & $76.99 \pm 0.13^{\mathrm{a}}$ & $70.67 \pm 0.66^{\mathrm{e}}$ \\
\hline DZ-Cr-438 & $48.14 \pm 0.22^{b}$ & $4.78 \pm 0.07^{b}$ & $4.24 \pm 0.64^{\mathrm{a}}$ & $59.12 \pm 0.11^{\mathrm{d}}$ & $76.07 \pm 0.65^{d}$ \\
\hline DZ-Cr-425 & $50.15 \pm 0.95^{a}$ & $5.99 \pm 0.12^{\mathrm{a}}$ & $3.84 \pm 0.05^{\mathrm{a}}$ & $58.82 \pm 0.35^{\mathrm{ed}}$ & $82.56 \pm 0.51^{\mathrm{a}}$ \\
\hline DZ-Cr-43B & $50.85 \pm 0.45^{\mathrm{a}}$ & $5.19 \pm 0.29^{b c}$ & $4.04 \pm 0.23^{\mathrm{a}}$ & $58.18 \pm 0.33^{\mathrm{e}}$ & $80.32 \pm 0.19^{b}$ \\
\hline LSD & 0.87 & 0.42 & 0.67 & 0.83 & 0.92 \\
\hline
\end{tabular}

Note: WA = Water absorption, DDT $=$ Dough development time, DST= Dough stability time, MTI=Mixing tolerance index, FQN=Farinograph quality number. Within a column, values with different superscriptletters havesignificant $(\mathrm{P}<0.05)$ differences.

\subsection{Water Absorption}

Water absorption is the point chosen by the baking industry which represents a target water-to-flour ratio in bread dough. It is important to determine taste and texture of flour and dough performance during proofing and baking. The measured water absorption capacity of the different teff flours dough is presented in Table 3 . The values were 47.37, $50.11,48.14,48.14,50.15$ and $50.85 \%$ for varieties Quncho (DZ-Cr-387), Felagot (DZ-Cr-442), Tesfa (DZ-Cr-457), Kora (DZ-Cr-438), Dukem (DZ-Cr-425) and Dagme (DZ-Cr-43B), respectively. There were significant $(\mathrm{P}<0.05)$ differences among water absorption capacityof the varieties. Dagme (DZ-Cr-43B) had the highest value (50.85\%) and Quncho DZ-Cr-387) having the lowest value (47.36\%) [39]

\subsubsection{Dough Development Time}

Dough development time is the time from the first addition of water to the time the dough reaches the point of greatest torque. The measured of dough development time teff flours are presented in Table 3 . There were significant $(\mathrm{P}<0.05)$ differences among the varieties on the dough development time of the teff flour dough. The longest time (5.99 min) was recorded for Dukem (DZ-Cr-425) whereas Quncho (DZ-Cr387) having the shortest dough development time. The longest DDT for this flour could be due to the lowest fraction of teff flour dough in which resulted in the lowest gluten content which absorbs the water. Dough development time increases with the increase in the proteolytical degradation of protein [40]. This is also may be due to decrease in their gluten contents and weakening of protein network due to proteolytical activity of composite flour. These results were found to be the range between 4.5 and $6.5 \mathrm{~min}$ who reported by [41].

\subsubsection{Dough Stability}

Dough stability time is the time in minutes during which the curve remains on $500 \mathrm{BU}$ line. The measured dough stability time of the teff flours dough are displayed in Table 3. The values were 3.99, 3.64, 3.62, 4.24, 3.84 and $4.04 \mathrm{~min}$ for varieties Quncho (DZ-Cr-387), Felagot (DZ-Cr-387), Tesfa (DZCr-457), Kora (DZ-Cr-438), Dukem (DZ-Cr-425) and Dagme (DZ-Cr-43B), respectively. There were no significant $(\mathrm{P}>0.05)$ differences among the varieties [41].

\subsubsection{Mixing Tolerance Index}

Mixing tolerance index is used by bakers to determine the amount that dough was softening over a period of mixing. The mixing tolerance index results of the flours are shown in Table 3. The values were 68.69, 74.58, 76.99, 59.12, 58.82 and 58.18 FU for varieties Quncho (DZ-Cr-387), Felagot (DZ-Cr-442), Tesfa (DZ-Cr-457), Kora (DZ-Cr-438), Dukem (DZ-Cr-425) and Dagme (DZ-Cr-43B), respectively. There were significant $(\mathrm{P}<0.05)$ differences among the varieties. Tesfa (DZ-Cr-457) having the largest value (76.99 FU) whereas Dagme (DZ-Cr-43B) the shortest value (58.18 FU) of the varieties. These results were found to be the range between 44.23 and $80.21 \mathrm{FU}$ reported by [42] teff flour blend with wheat flour dough.

\subsubsection{Farinograph Quality Number}

Farinograph quality number is the point of the curve in which the curve has decreased by $30 \mathrm{FU}$ after the maximum (based on the line of the diagram). Thus weak flour weakens early and quickly giving low quality number. Strong flour weakens late and slowly indicting a high quality number. The farinograph quality number results of the teff flours dough are presented in Table 3. The values were 77.94, 77.47, 76.07, 70.67, 82.56 and 80.32 FU for varieties Quncho (DZCr-387), Felagot (DZ-Cr-442), Tesfa (DZ-Cr-457), Kora DZCr-438), Dukem (DZ-Cr-425) and Dagme (DZ-Cr-43B), respectively. There were significant $(\mathrm{P}<0.05)$ differences among the varieties. Dukem (DZ-Cr-425) having the highest value (82.56 FU) whereas Kora (DZ-Cr-438) the lowest value $(70.67 \mathrm{FU})$. These results were found to be within the range between 40 and $115 \mathrm{FU}$ reported by [43] for blend both teff flour and soft wheat flour dough.

\section{Conclusions}

Teff is one of the major and indigenous cereal crops in Ethiopia. It is a unique durable crop grown over a wide range of environmental conditions in Ethiopia and has been utilized as food and supplements for majority of the human diet in Ethiopia. This study was conducted to generate information on some engineering properties of teff [Eragrostis teff (Zucc.) Trotter] grain and its flour. Six teff varieties namely Quncho (DZ-Cr-387), Felagot (DZ-Cr-442), Tesfa (DZ-Cr-457), Kora (DZ-Cr-438), Dukem (DZ-Cr-425) and Dagme (DZ-Cr-43B). 
The results were reported as an average value of triplicate analysis of (mean \pm SD) and were analyzed by Fisher's Least Significance Difference (LSD) method and at statistical significance of $\mathrm{P}<0.05$. The functional and rheological properties of the flours and dough expected of the teff grains. The color data showed that the varieties vary in the color of their flours which could be reflected on the processed products. The whiteness values as well as the $a^{*}$ and $b^{*}$ show that the white starch color is strongly diluted by the color of the nonwhite pigments found on the cover of the grains. This is also supported by the high fiber contents of the flours recorded in the study. All in all valuable information have been obtained about the teff grains that are of high importance in industrial processing of the grain to various products.

\section{References}

[1] Bultosa, G. 2007. Physico-chemical characteristics of teff grain and flour in 13 teff [Eragrostis teff (Zucc.) Trotter] grain varieties. Applied Sciences Research, 3 (12): 2042-2051.

[2] Shumaila Jan, Syed Insha and Saxena. D. C. 2015. Effect of Physical Properties on Flow ability of Commercial Rice Flour/Powder for Effective Bulk Handling. International Journal of Computer Applications, 0975 - 8887.

[3] Oladele, A. K., and Aina, J. O., 2007. Chemical Composition and Functional Properties of Flour Produced from Two Varieties of Tigernut (Cyperus esculentus). African Journal of Biotechnology, 6 (21) 2473-2476.

[4] Yu, J. K., Sun, Q., Rota, M., Edwards, H., Hailu, T., and Sorrells, M. E., 2006. Expressed sequence tag analysis in teff (Eragrostis teff (Zucc.) Trotter). Genome 49, 365-372.

[5] Sonaye, S., \& Baxi, D. 2012. Particle Size Measurement and Analysis of Flour. International Journal of Engineering and Applications, Vol 2 (3) pp. 1839-184.

[6] Laike, K, Solomon, W, Geremew, B and Senayit, Y. (2010). Effect of extrusion operating conditions on the physical and sensory properties of tef (Eragrostis tef [Zucc.] Trotter) flour extrudates. Ethiopian Journal of Applied Sciences and Technology, 1 (1): 27-38.

[7] Omima E. Fadlallah, Abdullahi H. El Tinay and Elfadil E. Babiker. (2010). Biochemical Characteristics of Sorghum Flour Fermented and/or Supplemented with Chickpea Flour, International Journal of Biological and Life Sciences. 6, 2125 .

[8] Munteanu M., Voicu Gh., Ștefan E. M., and Constantin G. A., 2015. Farinograph characteristics of wheat flour dough and rye flour dough, International Symposium ISB-INMA-TEH, pp. 645-650, 2015.

[9] Mirhosseini, H. and Amid, B. T. 2013. Effect of different drying techniques on flowability characteristics and chemical properties of natural carbohydrate-protein gum from durian fruit seed. Mirhosseini and Amid Chemistry Central Journal 7 (1): $1-14$.

[10] Zanatta, E. R.; Reinehr, T.; Silva, E., 2016, Kinetic studies of thermal decomposition of sugarcane bagasse and cassava bagasse. JTherm Anal Calorim 125, 437-445.
[11] Wookeun, B.; Jongho, K.; Jinwook, C., 2014, Production of granular activated carbon from food processing wastes (walnut shells and jujube seeds) and its Adsorptive properties. Journal of the air and waste management association 64, 879-886.

[12] Chinma, C. E., Abu, J. O. and Ojo, J. A. 2010. Chemical, Functional and Pasting Properties of Starches from Brown and Yellow Tigernuts (Cyperus esculentus). Nigerian Food.

[13] Collar, C. 2003. Significance of viscosity profile of pasted and gelled formulated wheatdoughs on bread staling. European Food Research and Technology, 216, 505-513.

[14] Ranghunath T. Mahajan and Gunjan M. Chaudhari (2014): Plant latex as vegetable source for milk clotting enzymes and their use in cheese preparation. International journal of advanced research, volume 2, issue 5: 1173-1181.

[15] Fano Dargo. 2013. Gain in grain yield potential and associated traits of tef [Eragrostistef (Zucc.) Trotter] in Ethiopia, MSc. Thesis, School of Plant Sciences, School of Graduate Studies, Haramaya University, Haramaya, Ethiopia.

[16] Shimelis, E., Meaza, M. and Rakishit, S. 2006. Physicochemical properties, pasting behaviour and functional characteristics of flours and starches from improved bean (Phaseolus vulgaris L.) varieties grown in East African. CIGR E- Journals 8: 1-18.

[17] Kaur, M., and Singh, N. 2005. Studies on functional, thermal and pasting properties of flours from different chickpea (Cicer arietinum L.) cultivars. Food Chemistry. 91: 403-411.

[18] MoA. 2014. Ministry of Agriculture, Plant Variety Release, Protection and Seed Quality Control Directorate, Crop Variety Register, Issue No. 17, June 2014, Addis Ababa, Ethiopia.

[19] MoA. 2015. Ministry of Agriculture, Plant Variety Release, Protection and Seed Quality Control Directorate, Crop Variety Register, Issue No. 17, June 2014, Addis Ababa, Ethiopia.

[20] Verma, A. K., Rituparna, B., and Sharma, B. D. (2012). Quality of Low Fat Chicken Nuggets: Effect of Sodium Chloride Replacement and Added Chickpea (Cicer arietinum L.) Hull Flour. AsianAustralian Journal of Animal Science, 25 (2): 291-298.

[21] Charunuch, C., Limsangouan, N., Prasert, W. Wongkrajang, (2014). Optimization of extrusion conditions for ready-to-eat breakfast cereal enhanced with defatted rice bran. International Food Research Journal 21 (2): 713-722.

[22] Ogbonnaya, C., Belinda, O., Aturu, N., Chukwu., (2012). Sensory Evaluation Of Honey Sold In Different Locations In Nigeria. Academic Research International, ISSN-L: 22239553, ISSN: 2223-9944 Vol. 2.

[23] Alabi, A. O., Babalola, K. A. Jimoh, K. O., Elutilo, O. O., Adeoti, A. O. 2015. Nutritional, Physico-Chemical and Sensory Properties of Yam Flour Dough Fortified with Moringa Oleifera Seed Flour. Science and Engineering Perspectives SEP. Vol. 10, 2015 ISSN: 1115 - 8336.

[24] Muthia, D., Nurul, H. and Noryati, I. (2010). The effects of tapioca, wheat, sago and potato flours on the physicochemical and sensory properties of duck sausage. Journal of International Food Research, 17: 877-884.

[25] Ajatta, M. A., Akinola, S. A. and Osundahunsi, O. F. 2016. Proximate, functional and pasting properties of composite flours made from wheat, breadfruit and cassava starch applied Tropical Agriculture Volume 21, No. 3, 158-165. 
[26] Fano Dargo. 2013. Gain in grain yield potential and associated traits of tef [Eragrostis tef (Zucc.) Trotter] in Ethiopia, MSc. thesis, School of Plant Sciences, School of Graduate Studies, Haramaya University, Haramaya, Ethiopia.

[27] Sirawdink, F. and Ramaswamy. S. (2011). Protein rich extruded products from tef, corn and soy protein isolate blends. Ethiopian Journal of Applied Science and Technology. 2 (2): 75 - 90 (2011)

[28] Emmanuel, O. A., Clement, A., Agnes, S. B., ChiwonaKarltun, L. and Drinah, B. N. 2012. Chemical composition and cyanogenic potential of traditional and high yielding CMD resistant cassava (Manihot esculenta Crantz) varieties. International Food Research Journal, 19 (1): 175-181.

[29] Kindinew. D., 2015. Evaluation of Pumpkin Supplementation Levels with Wheat Flour on Proximate Composition, Functional and Sensory Attribute of Leavened bread. M. Sc. Thesis.

[30] Jangchud, K., Phimolsiripol, Y. and Haruthaithanasan, V. 2003. Physicochemical properties of sweet potato flour and starch as affected by blanching and processing. Starch/Stärke, 55 (6): 258-264.

[31] Aprianita, A., Purwandari, U., Watson, B. and Vasiljevic, T. 2009. Physico-chemical properties of flours and starches from selected commercial tubers available in Australia. International Food Research Journal 16 (4): 507-520.

[32] Bultosa, G., A. N. Hall and J. R. N. Taylor, 2002. Physicochemical characterization of grain Teff [Eragrostis teff (Zucc.) Trotter] starch. Starch/Stärke, 54: 461-468.

[33] Adebowale, Abdul-Rasaq A, M Naushad Emmambux, Mervyn Beukes, and John Taylor. 2011. Fractionation and Characterization of Teff Proteins. Journal of Cereal Science. 54 (3): 380-386.

[34] Liang, X. and King, J. M., 2003. Pasting and Crystalline Property Differences of Commercial and Isolated Rice Starch B. I. Offia-Olua 1604 with Added Amino Acids. Journal of Food Science, 68, 832-838. http://dx.doi.org/10.1111/j.13652621.2003.tb08251.x
[35] Mariam I. O. Mohammed, Abdelmoneim I. Mustafa and Gammaa A. M. Osman., 2009. Evaluation of wheat breads supplemented with Teff (Eragrostis teff (ZUCC.) Trotter) Grain flour. Australian Journal of Crop Science 3 (4): 207-212 (2009).

[36] Ndie EC, Nnamani CV, Oselebe HO., 2010. Some physicchemical characteristics of defatted flours derived from African walnut (Tetracarpidium conoforum): An underutilized legume. Pak. J. Nutr. 9 (9): 909-911.

[37] Rosa Nilda CHÁVEZ-JÁUREGUI, Raul Dias SANTOS, Alessandra MACEDO, (2010). Effects of defatted amaranth (Amaranthus caudatus L.) snacks on lipid metabolism of patients with moderate hypercholesterolemia.

[38] Monica, W. Mburu, Nicholas, K. Gikonyo, Glaston M. Kenji and Alfred M. Mwasaru, (2011). Properties of a Complementary Food based on Amaranth Grain (Amaranthus cruentus) Grown in Kenya. Journal of Agriculture and Food Technology, 1 (9) 153-178.

[39] Thiele, C.; M. G. Ganzle and R. F. Vogel, 2002. Contribution of sourdough lactobacilli, yeast, and cereal enzymes to the generation of amino acids in dough relevant for bread flavor. Cereal Chemistry, 79: 45-51.

[40] Jorge, Alvaro, Roberto, (2012). Optimization of Extrusion Process for Producing High Antioxidant Instant Amaranth (Amaranthus hypochondriacus L.) Flour Using Response Surface Methodology. Applied Mathematics. 3: 1516-1525.

[41] Jose, (2011). Use of Amaranth, Quinoa and Kañiwa in Extruded Corn Snacks. University of Helsinki, Department of Food and Environmental Sciences. ISSN 0355-1180.

[42] Solomon., 2015. The effect of wheat, teff and soybean flours blending ratio and baking temperature on bread quality M. Sc. Thesis.

[43] Maghirang, E. B., G. L. Lookhart, S. R. Bean and R. O. Pierce, 2006. Comparison of quality characteristics and bread making functionalityof hard red winter and hard red spring wheat. Cereal Chemistry, 83 (5): 520-528. 